\title{
Changes in microglia activity of rat brain induced by Macrovipera lebetina obtusa venom
}

\author{
Anna A. Darbinyan, Marina V. Antonyan, Hasmik R. Koshatashyan, Susanna S. Gevorgyan, \\ Hovhannes V. Arestakesyan, Zaruhi I. Karabekian, Naira M. Ayvazyan, Armen V. Voskanyan \\ Orbeli Institute of Physiology, National Academy of Sciences, Yerevan 0028, Armenia.
}

Correspondence to: Dr. Armen V. Voskanyan, Orbeli Institute of Physiology, National Academy of Sciences, Yerevan 0028, Armenia. E-mail: arminvosking@gmail.com

How to cite this article: Darbinyan AA, Antonyan MV, Koshatashyan HR, Gevorgyan SS, Arestakesyan HV, Karabekian Zl, Ayvazyan NM, Voskanyan AV. Changes in microglia activity of rat brain induced by Macrovipera lebetina obtusa venom. Neuroimmunol Neuroinflammation 2018;5:41. http://dx.doi.org/10.20517/2347-8659.2018.33

Received: 8 Jun 2018 First Decision: 27 Aug 2018 Revised: 7 Sep 2018 Accepted: 10 Sep 2018 Published: 29 Sep 2018

Science Editor: Athanassios P. Kyritsis Copy Editor: Yuan-Li Wang Production Editor: Huan-Liang Wu

\begin{abstract}
Aims: The microglia activity of rat brain following exposure of the Macrovipera lebetina obtusa venom was investigated.

Methods: Histochemical analysis of brain microcirculatory bed staining by $\mathrm{Ca}^{2+}$ ATPase method for variable doses after intraperitoneal injections given for different time periods was used. The hemorrhagic activity of snake venom metalloproteinases was tested. Toxicological data were calculated using Behrens and Miller-Tainter methods. Surface, size of brain microglial cells (MGCs) and staining intensity were quantified using ImageJ software.
\end{abstract}

Results: The vasodestructive action of the venom resulted in changes in ATPase activity. The intensity of staining of rat brain microcirculatory bed was venom dose-, and time-dependent. Increased activity of MGCs in hemorrhagic loci of different regions of venom affected brain was also demonstrated.

Conclusion: The activation of microglia and changes of its form, size, and position strongly correlates with hemorrhage-induced cerebrovascular damage.

Keywords: Macrovipera lebetina obtusa venom, toxicity $L_{50}$, hemorrhage, metalloproteinase, rat brain microcirculatory bed, microglia 


\section{INTRODUCTION}

The Vipers are the lone family of venomous snakes found in Armenia. The main action of viper venoms is related to protein-degrading proteases, which cause local necrosis, systemic cardiovascular damage, and disruption of the blood-clotting system ${ }^{[1]}$. The whole venom of Caucasian Levantine viper [syn.: bluntnosed viper, Macrovipera lebetina obtusa (MLO)] contains many enzymatically active proteins and different polypeptides [Figure 1] with a variety of effects on cells and organs, including pronounced hemorrhagic effect $^{[2,3]}$. Macrovipera lebetina species venom contains snake venom metalloproteinases (SVMP $)^{[4,5]}$ which are $\mathrm{Zn}^{2+}$-containing, $\mathrm{Ca}^{2+}$-dependent enzymes that differ in domain structure: some of them contain just metalloproteinase domain, others contain metalloproteinase domain and non-catalytic domains. MLO venom contains only two out of four types of SVMPs: P-I and P-III ${ }^{[2]}$. Metalloproteinase P-I has only catalytic domain ${ }^{[6,7]}$ and consitutes more than one-quarter of the whole MLO venom.

The P-III is characterized by proteolytic enzyme property, high ability to bind to the substrate ${ }^{[6,8]}$ and high hemorrhagic activity (with rare exceptions ${ }^{[9]}$ ). Together PI and PIII are making up approximately one-third of the entire contents of the MLO venom. SVMPs, which are secretory proteinases, cause hemorrhagic injuries, splitting the components of the basement membrane and disrupting their interaction with endothelial cells ${ }^{[10]}$. In addition, they induce muscle necrosis, skin damage, and inflammation. Some SVMPs induce apoptosis in human umbilical vein endothelial cells ${ }^{[11]}$. Moreover, SVMPs interact with matrix metalloproteinases (MMPs) of a prey. MMPs are carrying out tissue remodeling, angiogenesis, cell proliferation, migration, differentiation, apoptosis, and in curbing the growth of tumors ${ }^{[12]}$. They are involved in the cleavage of membrane receptors, ligand release, as well as in the activation/deactivation of the chemokines and cytokines ${ }^{[13]}$. SVMP P-I and P-III can trigger secretion of prey's MMP-2 and MMP-9, which together with venom MPs may destroy extracellular matrix or VE-cadherins ${ }^{[4]}$. These and other cadherins ( $\beta$ and $\gamma$ ) are denatured leading to increased intracellular permeability ${ }^{[1]]}$. During such damage of brain tissue, microglia plays a critical role in the protection of brain from the action of harmful factors of the venom ${ }^{[14-16]}$.

Mechanisms by which different doses of snake venom, and particularly, SVMPs affect or disrupt the microvasculature of brain and cause hemorrhage have not been fully elucidated. The goal of our investigation was to assess hemorrhagic effects of MLO venom on rat brain given at different doses and for different periods when administered via intraperitoneal (IP) route.

\section{METHODS}

\section{Animals}

This study was conducted in accordance with "Principles of Laboratory Animal Care" and as carried out in accordance with the European Communities Council Directive of September 222010 (2010/63/EU). Sixtytwo adult Wistar albino male rats were used in this study.

\section{Reagents}

MLO venom was milked and dried in the Laboratory of Physiologically Active Substances Purification, Certification and Standardization (PAS PCS) of Orbeli Institute of Physiology of National Academy of Sciences of Armenia. Snakes were supplied by the licensed catcher "GEBEVSS" Ltd., Armenia. Other reagents were purchased from "Sigma-Aldrich", "Merck" "Reanal" and "H. Lundbeck A/S" companies as indicated. All other chemicals were of analytical or sequencing grade.

\section{Verification of venom hemorrhagic activity in vivo}

The hemorrhagic activity of SVMPs was tested in vivo by a modified method of Kondo et al. ${ }^{[17]}$. In brief, 2 rats (around $250 \mathrm{~g}$ ) were anesthetized with Nembutal (pentobarbital, at a dose of $40 \mathrm{mg} / \mathrm{kg}$ ) and $4 \mathrm{~cm}^{2}$ of dorsal skin was chemically depilated ("Veet", Reckitt and Benckizer, France). $0.1 \mathrm{~mL}$ aliquots of a 


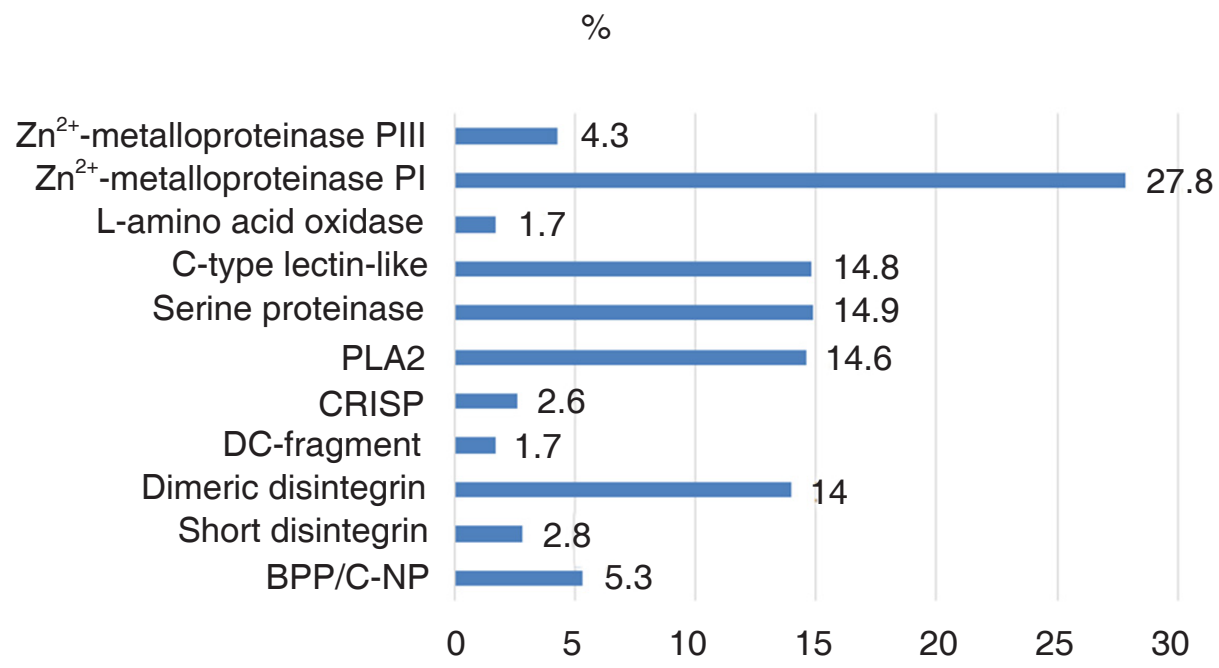

Figure 1. Percentile of venom of Macrovipera lebetina obtusa components ${ }^{[2]}$. (BPP/C-NP: bradykinin potentiating/C-natriuretic peptide; CRISP: cysteine-rich secretory protein; PLA2: phospholipase $A_{2}$ )

physiological solution containing $2.0 \mathrm{mg}$ venom were injected subcutaneously (SC). After $2 \mathrm{~h}$ the animals were euthanized and dorsal skin was removed. Hemorrhagic spots were identified and counted on the inner surface of the skin.

\section{Verification of venom toxicity in vivo}

Experiments were done on 30 adult male rats weighing 220-250 g to determine MLO venom toxicity $\mathrm{LD}_{50}$ (IP injection). Five doses were chosen for determination of $\mathrm{LD}_{50}$ starting from $100 \%$ vitality to $100 \%$ mortality. In our study for estimation of $\mathrm{LD}_{50}$ of venom, 5 doses were given intraperitoneally to 5 groups of rats, 6 in each group. Each rat in the first group was injected IP with MLO venom at a dose of $1 \mathrm{mg} / \mathrm{kg}$. In the second group rats were injected with $2 \mathrm{mg} / \mathrm{kg}$, the third: $3 \mathrm{mg} / \mathrm{kg}$, fourth: $4 \mathrm{mg} / \mathrm{kg}$ and fifth: $5 \mathrm{mg} / \mathrm{kg}$ respectively. The number of dead animals was recorded at $24 \mathrm{~h}$ and the percent of mortality in each group was calculated. Percentage mortalities were transformed to probits and corrected formula for $0 \%$ mortality $[100(0.2 / \mathrm{N})]$ and $100 \%$ mortality $[100(\mathrm{~N}-0.25 / \mathrm{N})]$ was used. Approximate standard error was calculated from following formula:

Approx. SE of $\mathrm{LD}_{50}=\left(\log \mathrm{LD}_{84}-\log \mathrm{LD}_{16}\right) /(2 \mathrm{~N})^{1 / 2}$,

where $\mathrm{N}$ is number of animals in each group.

$\mathrm{LD}_{16}, \mathrm{LD}_{84}$ and final data were calculated using table of probits for Behrens and Miller-Tainter methods ${ }^{[18]}$.

\section{Histochemical studies}

Thirty rats were used for histochemical studies. The animals were kept in the nursery for laboratory animals of Institute of Physiology NAS of Armenia. Daylight and diet were conditioned in accordance with the Animal Protocol of the Institute. Venom was injected in at 2.0, 3.0 and $5.0 \mathrm{mg} / \mathrm{kg} \mathrm{IP}$, which was approximately equal to 1.0, 1.5 and $2.5 \mathrm{LD}_{50}$ for MLO venom. Animals were divided into 5 groups with 6 animals in each: Group \#1 was a control group with intact rats that have only been anesthetized before they were sacrificed. The other 4 experimental groups were set as follows: Group \#2, \#3 and \#4 were injected with different doses of MLO venom (1.0 LD $\mathrm{L}_{50}, 1.5 \mathrm{LD}_{50}$, and $2.5 \mathrm{LD}_{50}$ respectively) followed by extraction of the brain $2 \mathrm{~h}$ post-injection. Group \#5 was injected with a dose of MLO venom $\left(2.5 \mathrm{LD}_{50}\right)$, however, brains were isolated $1 \mathrm{~h}$ post-injection. 


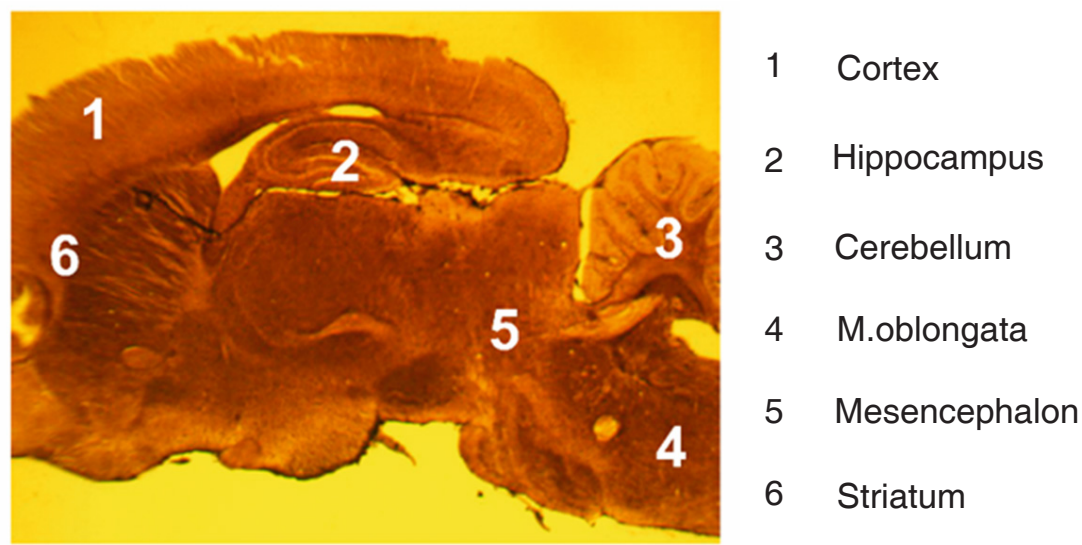

Figure 2. Investigated areas of rat brain

The animals were anesthetized (pentobarbital, at a dose of $40 \mathrm{mg} / \mathrm{kg}$ ) and sacrificed by decapitation after one or two hours. The brains were excised, fixed in $5 \%$ solution of formaldehyde, frozen, and then sliced. The method developed by Chilingaryan et al. ${ }^{[19]}$ was used. This method is very practical for identifying intraorgan microcirculatory bed. Vessel staining is based on the activity of phosphatases (specifically ATPases) and precipitation of released phosphate with calcium ions at high $\mathrm{pH}(\mathrm{pH}$ 10.5-11.5). The resulting precipitate is subsequently converted to brown lead sulfide. The method provides selective, clear, and contrast detection of vascular capillary network in thick $(60-100 \mu \mathrm{m})$ sections of the brain. A major advantage is the possibility of simultaneous identification of various branches of the microcirculatory bed (arterioles, capillaries, venules). The intact brain tissue vessels were mostly semitransparent, so an increase of vessels staining density was estimated an indicator of venom action.

A modification of the original Chilingaryan et al.'. ${ }^{[19]}$ method is described in details below.

The brains of rats were fixed in a 5\% solution of neutral formalin (using tap water) for $24 \mathrm{~h}$. (Slices of 90 $\mu \mathrm{m}$ were prepared using freeze microtome). Slices were collected in a saline solution and transfered into incubation buffer [ $4 \mathrm{~mL} 4 \mathrm{~N} \mathrm{25 \%}$ ammonia solution; $2 \mathrm{~mL} 0.1 \mathrm{~mol} / \mathrm{L}$ calcium chloride solution; $2 \mathrm{~mL}$ adenosine triphosphate (ATP) solution ( $0.1 \mathrm{~mol} / \mathrm{L}$ fresh prepared solution of disodium salt of ATP) $+12 \mathrm{~mL}$ distilled $\mathrm{H}_{2} \mathrm{O}$ ] for $1.5 \mathrm{~h}$, then washed twice in distilled water for $2-5 \mathrm{~min} /$ wash and then immersed into a replacement lead solution, prepared as follows: to $100 \mathrm{~mL}$ of water add 2 drops of glacial acetic acid, then $2 \mathrm{~g}$ lead acetate, and then add $10 \mathrm{~mL} 1 \mathrm{~mol} / \mathrm{L}$ acetate buffer ( $\mathrm{pH}$ 6.2) and $15 \mathrm{~mL} 8 \%$ solution of ammonia acetate). The mixture is suitable for a long time and can be used repeatedly. In a specified mixture, slices remain for $1.5 \mathrm{~h}$. After washing in distilled water for 2-5 min, slices were immersed into $1 \%$ solution of sulfosalicylic acid on 2-3 min depending on the thickness of the slices. Thereafter the slices were washed twice in distilled water for 2-5 $\mathrm{min} /$ wash and were immersed into $2 \%-5 \%$ solution of sodium sulfide for 1-2 min. After all slices were rinsed in distilled water and transfered on glass. Then slices were dried for $1.5 \mathrm{~h}$ and overlayed with Canada balsam.

Different regions of rat brain were investigated: medulla oblongata, mesencephalon, cerebellum, striatum, hippocampus, and cortex in accordance with rat brain atlas ${ }^{[20]}$. Sagittal sections of rat brain allowed observation of all regions on the same histological slide [Figure 2].

Photomicrographs of brain slices were done using digital eyepiece FMA050 AmScope UCMOS09000KPB and lenses x6, x9, x20 and x40. Surface, size of brain microglial cells (MGCs) and staining intensity were quantified using ImageJ software ${ }^{[21]}$ [Figure 3]. Pixels were identified by converting the original color images to an 8-bit grayscale, followed by the application of an automatic threshold function of the ImageJ software. 

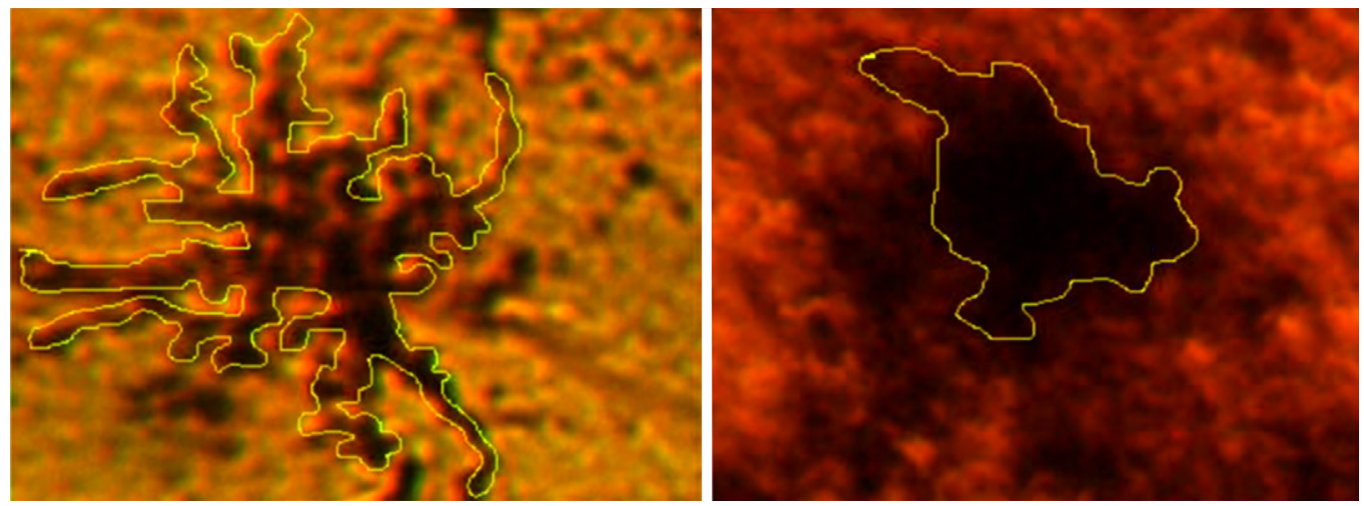

Figure 3. A sample of microglial cell contouring for footprint and linear dimensions measurement. The left slice - contoured cell of the brain, $1 \mathrm{~h}$ after injection, the right slice $-2 \mathrm{~h}$ after injection
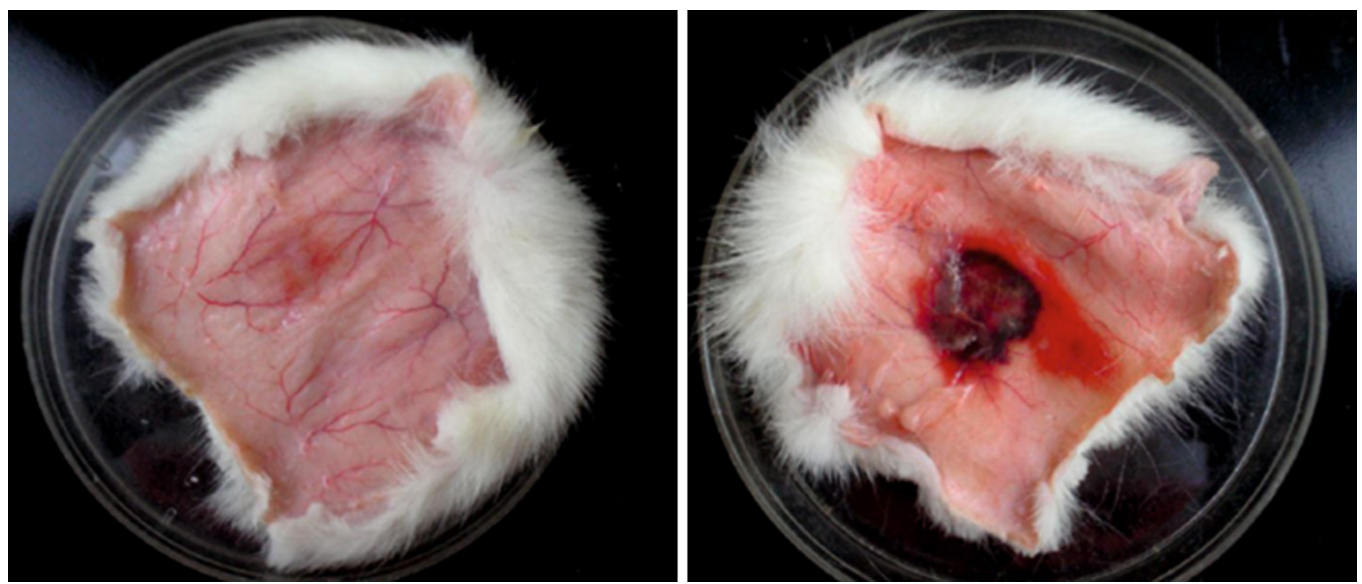

Figure 4. No hemorrhage is detected on the skin of sham-injected animals (left), however animals injected with $2.0 \mathrm{mg} / 0.1 \mathrm{~mL}$ of Macrovipera lebetina obtusa venom demonstrate significant hemorrhage after $2 \mathrm{~h}$ (right)

\section{Statistics}

The area, the perimeter and staining intensity of brains' MGCs were evaluated. Six separate viewfields were assessed for each intact and experimental animal. Means and standards error/deviation were quantified using ImageJ software and calculated for all groups using Student $t$-test. $P$-values less than 0.05 were considered as statistically significant.

\section{RESULTS}

\section{Hemorrhagic activity investigations}

First, we investigate the hemorrhagic activity of MLO venom. To that end, MLO venom was injected SC on the back of rats $(2.0 \mathrm{mg} / 0.1 \mathrm{~mL})$. After $2 \mathrm{~h}$, the back skin was removed and the inner surface of the skin was examined for the presence of hemorrhagic spot [Figure 4].

\section{Toxicological investigations}

The median lethal dose $\left(\mathrm{LD}_{50}\right)$ of MLO venom for intravenous injection (IV) was determined previously by two different groups. Archundia and coworkers in 2011 determine the $\mathrm{LD}_{50}$ of $\mathrm{MLO}$ venom to be $30.1 \mu \mathrm{g} /$ mouse ${ }^{[22]}$, whereas Kurtović et al. ${ }^{[23]}$ found $\mathrm{LD}_{50}$ to be $18.4 \mu \mathrm{g} /$ mouse. Considering this discrepancy and the absence of data on the IP route of venom administration in rats, we have tested and established toxicity $\left(\mathrm{LD}_{50}\right)$ for IP injection of MLO venom for mice and rats. 


\section{MLO venom toxicity $\mathrm{LD}_{50}, \mathrm{IP}$ : rats and mice}

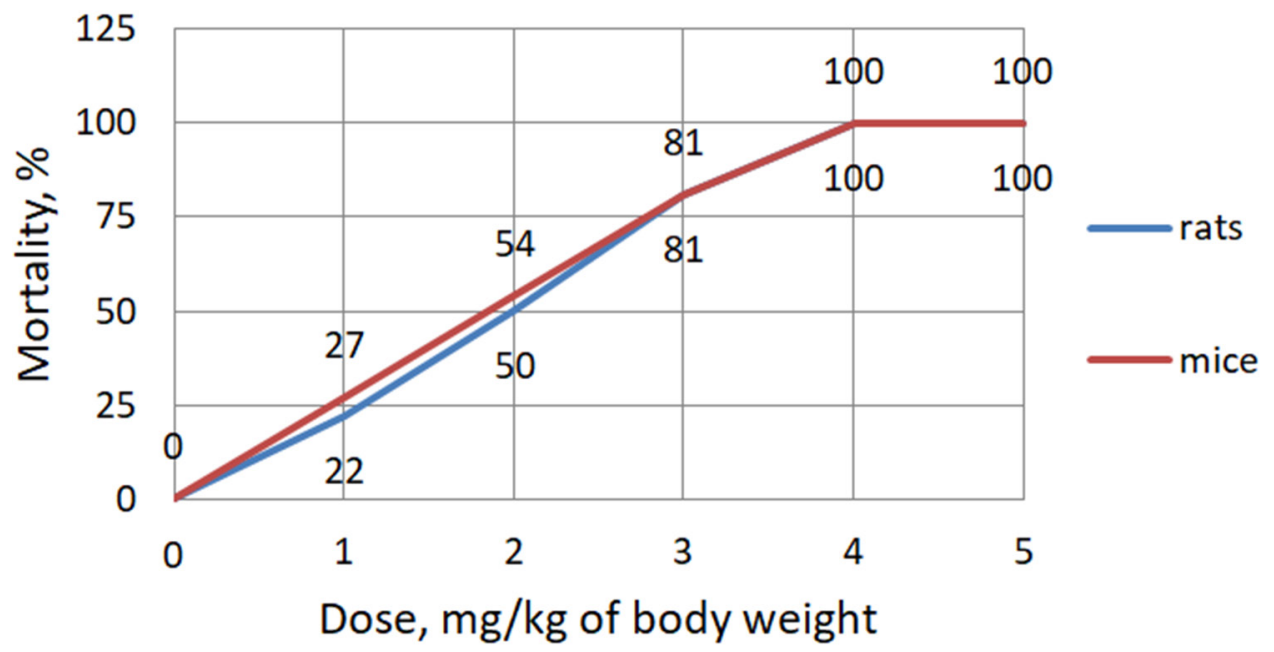

Figure 5. The toxicity of Macrovipera lebetina obtusa venom in mice and rats according to Behrens method

Table 1. Macrovipera lebetina obtusa venom toxicity $\mathrm{LD}_{50}$ calculated according to Miller-Tainter method

\begin{tabular}{llll}
\hline Calculation for rats & MLO venom & Calculation for mice & MLO venom \\
\hline Behrens calculated $L D_{50}$ & 2.0 & Behrens calculated $\mathrm{LD}_{50}$ & 1.85 \\
$\mathrm{LD}_{84}$ & 3.15 & $\mathrm{LD}_{84}$ & 3.1 \\
$\mathrm{LD}_{16}$ & 0.7 & $\mathrm{LD}_{16}$ & 0.6 \\
Standard error $(\mathrm{SE})$ & 0.1 & $\mathrm{SE}$ & 0.2 \\
Miller and Tainter calculated $\mathrm{LD}_{50}$ & 1.86 & Miller and Tainter calculated $\mathrm{LD}_{50}$ & 1.74 \\
$\mathrm{LD}_{50} \pm \mathrm{SE}$ & $1.86 \pm 0.1$ & $\mathrm{LD}_{50} \pm \mathrm{SE}$ & $1.74 \pm 0.2$ \\
\hline
\end{tabular}

The toxicity of MLO crude venom in mice according to Behrens method was $1.85 \mathrm{mg} / \mathrm{kg}$ and calculated by Miller-Tainter method was $\left(\mathrm{LD}_{50} \pm \mathrm{SE}\right) 1.74 \pm 0.2 \mathrm{mg} / \mathrm{kg}$. The toxicity of MLO crude venom in rats according to Behrens method was $2.0 \mathrm{mg} / \mathrm{kg}$ and by Miller-Tainter method was $\left(\mathrm{LD}_{50} \pm \mathrm{SE}\right) 1.86 \pm 0.1 \mathrm{mg} / \mathrm{kg}$ [Figure 5 and Table 1].

\section{Histochemical investigations of changes in microglia activity and microcirculatory bed of rat brain}

It is well known that main effect of venom depends on enzymatic (both time and dose-dependent) and nonenzymatic activity of specific low molecular weight peptides (dose dependent) ${ }^{[24]}$. Therefore, we performed histochemical investigations aimed at revealing changes in rat brain microcirculatory bed and activity of microglia. These experiments were done using variable doses of MLO venom given for indicated periods.

We compared data obtained after $1 \mathrm{~h}$ and $2 \mathrm{~h}$ after venom injection. After $2 \mathrm{~h}$ the results demonstrated well-defined picture of affected capillaries of the microcirculatory bed of blood vessels in various regions of the brain with activated, migrating MGC as dark amoeboid spots, especially at the points of contacting with vessels. The most venom affected blood vessels were observed in the deep structures of the brain and striatum. Blood vessels in the cerebellar and cerebral cortexes were less affected [Figure 6].

Comparative analysis of venom exposure of different doses on brain vessels and MGCs activity showed that lower doses (equivalent to 1.0 or $1.5 \mathrm{LD}_{50}$ ) had no dramatic effect on the brain tissue [Figure 7].

The increased activity of microglia was detected during exposure to the venom. The MGCs became well visible due to higher ATPase activity and, with time, more of these activated MGCs get into direct contact 
Intact

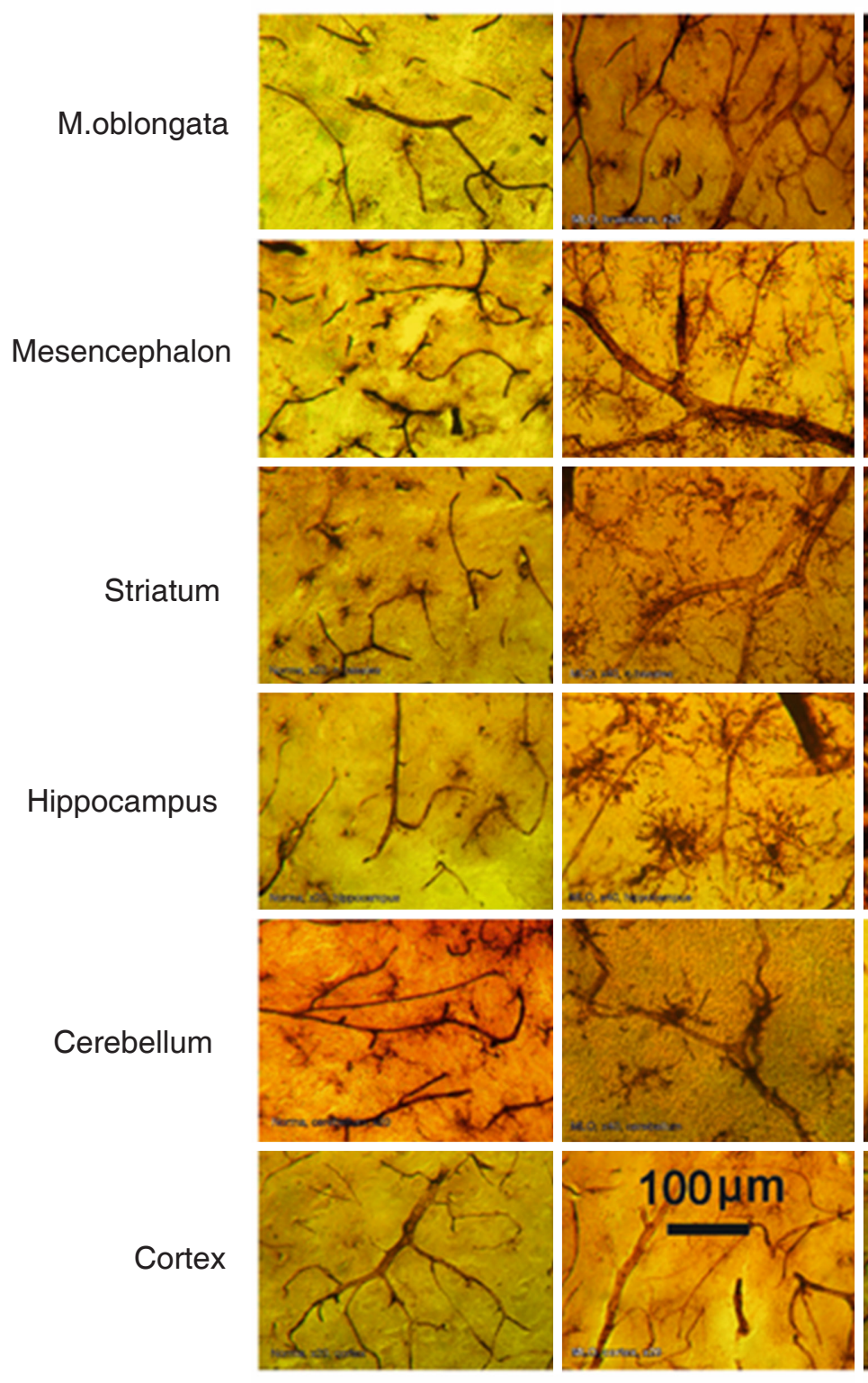

$1 \mathrm{~h}$
Dose $2.5 \mathrm{LD}_{50}$
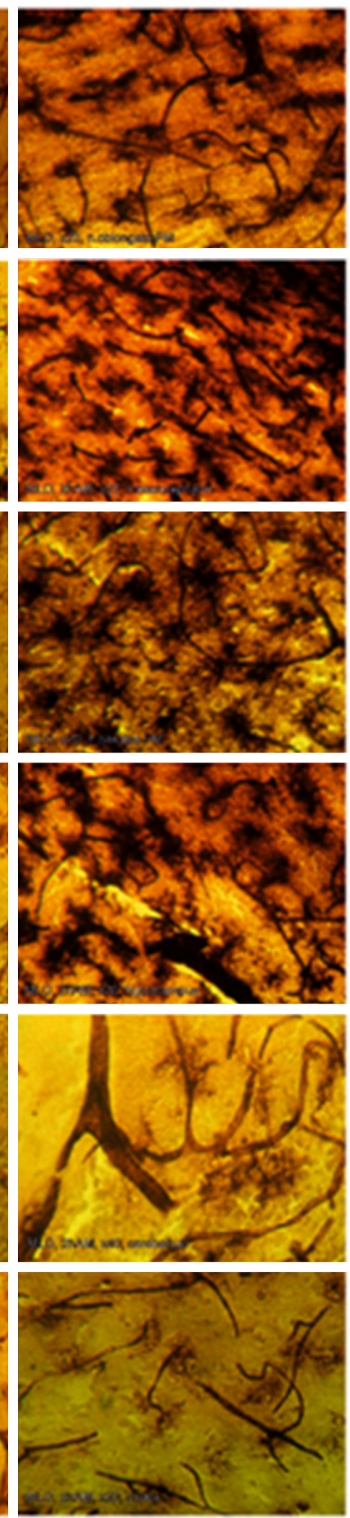

$2 \mathrm{~h}$

Figure 6. Comparative morphology of rat brain sections taken from indicated regions of an intact animal (left column) and from rats exposed to 2.5 $\mathrm{LD}_{50}$ dose of Macrovipera lebetina obtusa after $1 \mathrm{~h}$ and $2 \mathrm{~h}$ post injection (middle and right column respectively)

with capillaries [Figure 8].

A comparative study of the effects of different doses with the same time of exposition and the same doses for different times of exposition showed that ATPase and MGCs activation are both time- and dose-dependent.

Photomicrographs show that after the shorter exposure and/or smaller dose of MLO venom MGCs have accented ramifications and looked like stellar structures. This indicates a low level of ATPase activation in MGCs and neighboring vessels. In the case of larger dose and/or longer exposure to the venom, MGCs appear as massive dark spots [Figure 9]. 


\section{$2 \mathrm{~h}$}

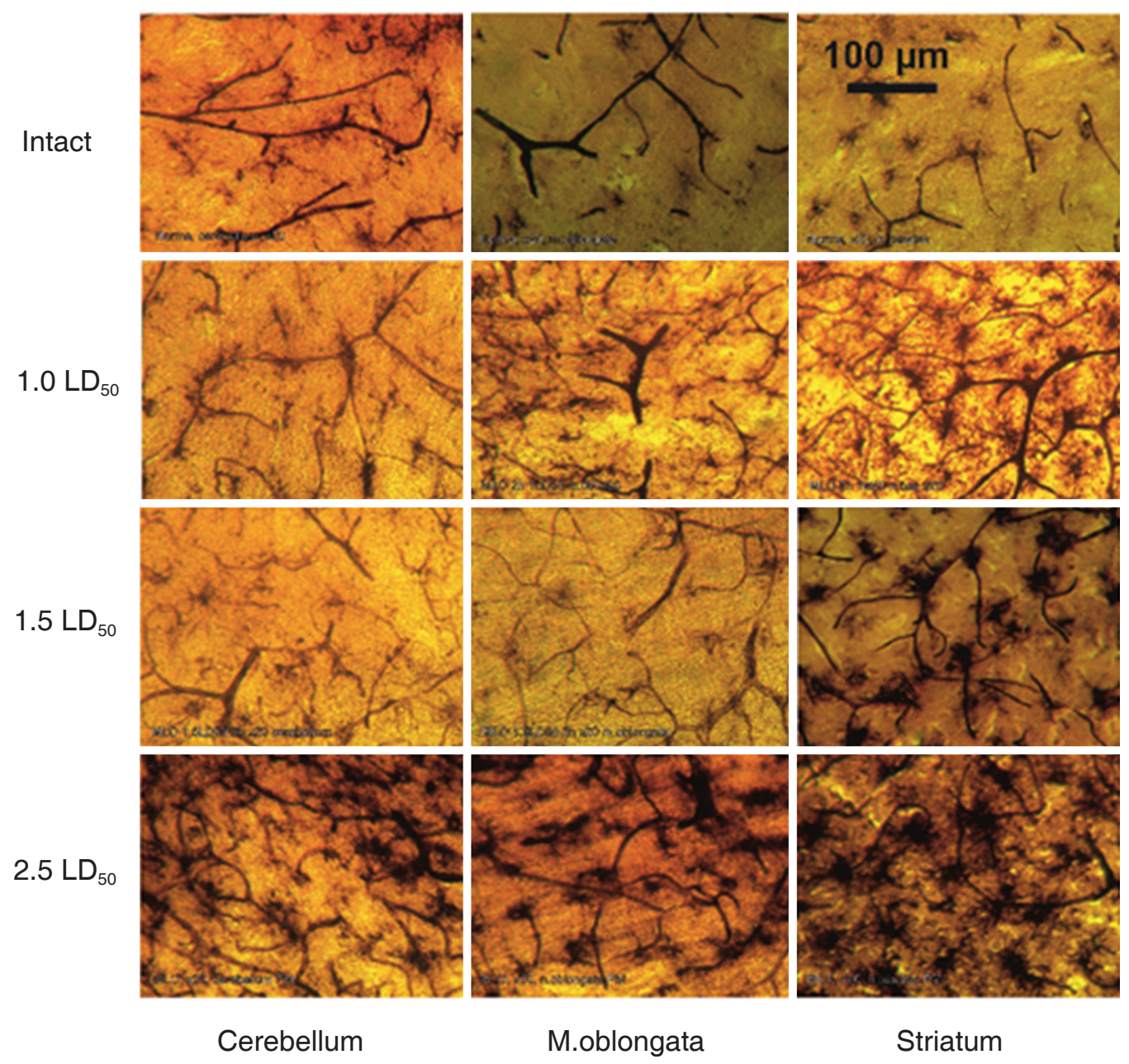

Figure 7. Morphology of three different areas of the rat brain upon exposure the Macrovipera lebetina obtusa venom at 1.0LD $50,1.5 L_{50}$, and $2.5 L_{50}$ $2 \mathrm{~h}$ after injection. Microglial cells activity is markedly elevated and similar only to higher dose 2.5 LD $_{50}$ and long period $2 \mathrm{~h}$ as well

Changes in the areas, occupied by MGCs show their transformation from stellar to amoeboid shape. This indicates the transition of "primed" MGCs ${ }^{[25]}$ into its activated state [Figure 10]. The mean perimeter of activated MGCs was 705.9 $\pm 165.7 \mu \mathrm{m}$ and the mean perimeter of amoeboid MGCs: $373.4 \pm 55.4 \mu \mathrm{m}, P<0.002$.

After MLO venom exposure, MGCs show changes similar to changes associated with other pathological processes, such as inflammation and hemorrhagic stroke ${ }^{[26]}$. Activation of MGCs correlates with an increase in ATPase activity. Specifically, an increase of venom dose, and/or the time of exposure results in the higher intensity of MGCs staining. To quantify the changes identified in photomicrographs the intensity of MGCs staining was examined. Collected images were processed by ImageJ to evaluate the corresponding level of MGCs activation [Figure 11].

The values shown are the percentile of the total area of the image occupied by the pixels representing glial cells and vessels with high levels of ATPase activity. ATPase activity of damaged vessels and activated MGCs lead to development of darker staining and indicates action of venom.

\section{Calculation of the quantitative parameters of MGCs' size and form}

To quantify the changes identified in microphotographs we delineated the MGCs. It is important to mention 


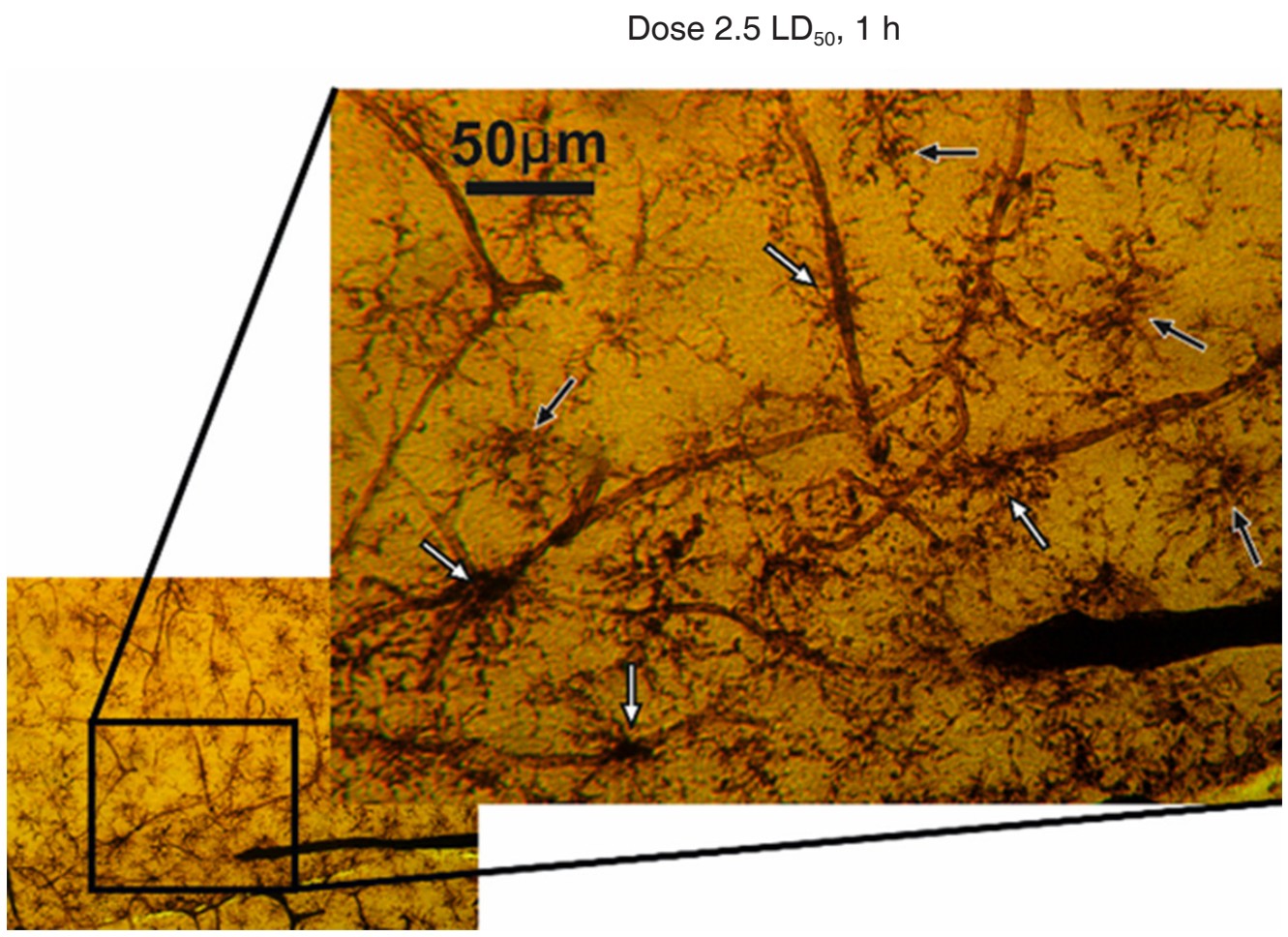

Figure 8. Hippocampal region of rat brain after $1 \mathrm{~h}$ of Macrovipera lebetina obtusa venom injection at $2.5 \mathrm{LD}_{50}$ dose. The black arrows show microglial cells in the middle of neighbor vessels area, white arrows show MGC in contact with capillaries

that we were not working with the real contours of cells, but rather with ATP-ase enzyme activity visualized as dark shapes of activated MGC. Reduction of the area, occupied by MGCs shows their transformation from stellar to amoeboid shape associated with corresponding stages of activity [Table 2]. The results demonstrate that general area occupied by stellar MGCs and amoeboid MGCs is $22334 \pm 5092$ and $6628 \pm$ 370 relative units respectively, i.e., area of amoeboid MGCs shrinks approximately 3 times when the target is reached.

In the case of MLO venom action, MGCs show changes similar to any other kind of pathological processes, including inflammation and hemorrhagic stroke as well ${ }^{[2]}$.

\section{DISCUSSION}

One of the major effects of MLO venom on brain tissue is the induction of hemorrhage. Metalloproteinases destroy basal membrane of blood vessels on which the endothelial cells are anchored. However, the targets of the MLO venom enzymes are not only the basement membrane proteins - collagen IV and laminin, but also proteins of endothelial cells - integrins and cadherins. In addition, when the destruction of the capillary bed begins, many penetrated substances also damage brain tissue. Specifically, fibrinogen and damaged by venom PLA $\mathrm{P}_{2}$ red blood cells get in the brain. Many different derivatives of damaged membranes such as lysophosphatidylcholine, arachidonic acid, platelet activating factor etc. infiltrate the brain tissue as well. In the case of more substantial damage, the infiltration of leukocytes into the brain tissue also occurs ${ }^{[27]}$. Moreover, serine proteases, $\mathrm{L}-\alpha$-amino acid oxidase and a cluster of other physiologically active substances, enter the brain tissue and destruct vital structures ${ }^{[2,28]}$.

During our investigation, we used doses of venom which impact brain tissue markedly enough to cause morphological changes. The maximal experimental dose was equal to $2.5 \mathrm{LD}_{50}$, and rats lived during 


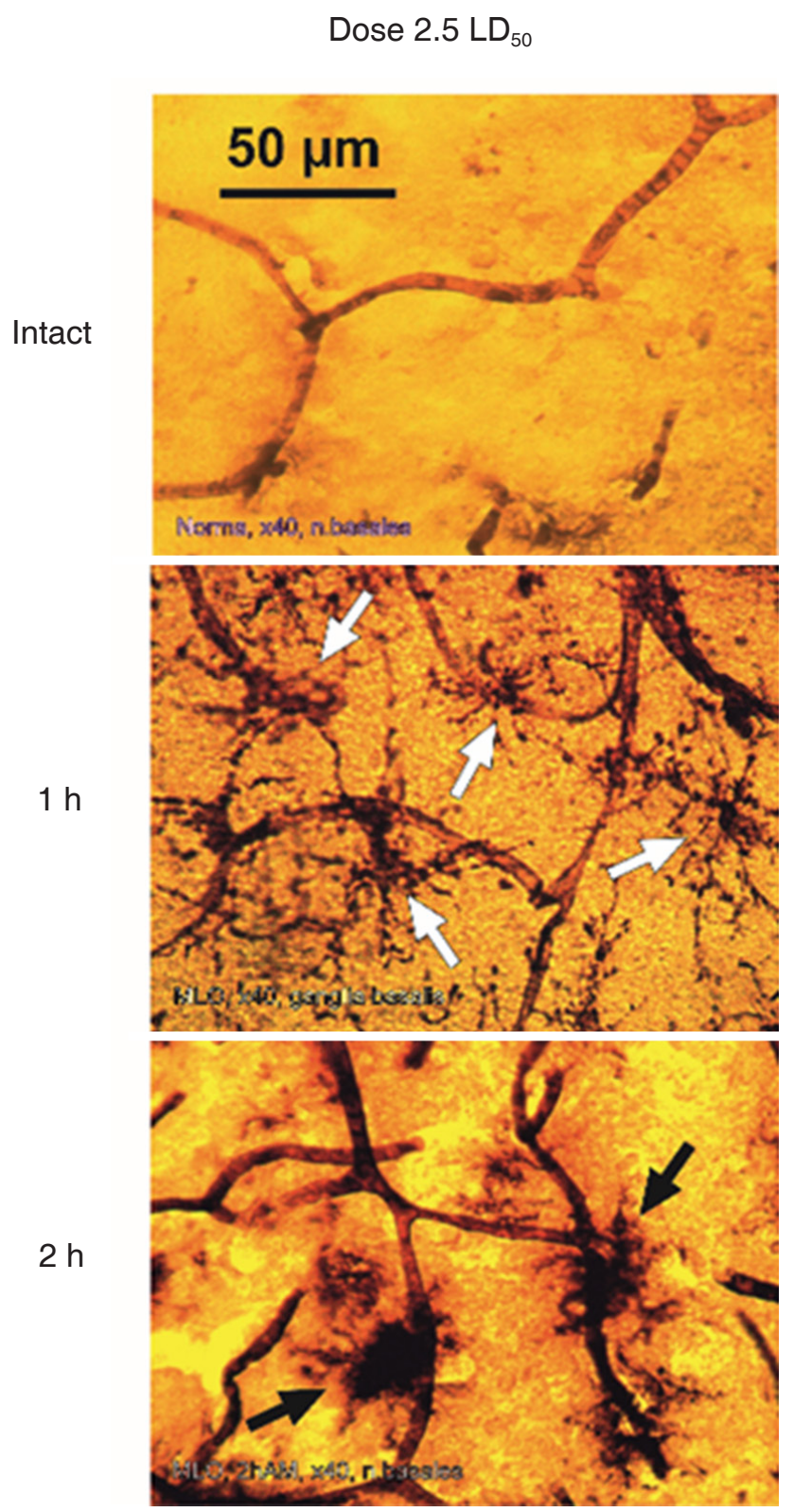

Figure 9. Microglial cells (MGCs) activation in striatum after $1 \mathrm{~h}$ and $2 \mathrm{~h}$ of venom injection. Macrovipera lebetina obtusa venom dose $2.5 \mathrm{LD}_{50}$. Activated/primed MGC are shown with white arrows, "proinflammatory state" ${ }^{\prime[39]}$ with black arrows

2-2.5 h, and sometimes longer. This gave an opportunity to take the animal brain antemortem and avoid post-mortem brain changes not associated with the effect of the venom. The method of the histochemical study of microcirculatory bed used in this study is based on the principle of detecting the activity of ATPase in the capillaries leading to deposition of lead sulfide as a contrast agent for light microscopy. However, it can also be used to stain activated microglia. "Resting" MGCs have relatively low metabolism and low level of ATPase activity, so virtually no microglia is detected by staining of the brain of intact animals ${ }^{[29,30]}$. However, analysis of brains of animals exposed to MLO venom clearly identifies activation of MGC in different stages ${ }^{[31]}$. Microglia can be activated in the presence of many damaging factors, for example, proinflammatory stimulation of lipopolysaccharide, ischemia, elevated concentrations of amyloid protein, fibrinogen, thrombin, or ATP, or any other signaling molecule, which induce receptors expression on MGC. Our results corroborate with results of other investigators, which were obtained in both in vitro and in vivo models of activated microglia ${ }^{[32]}$. There is also data about the activation of microglia in the hippocampus 

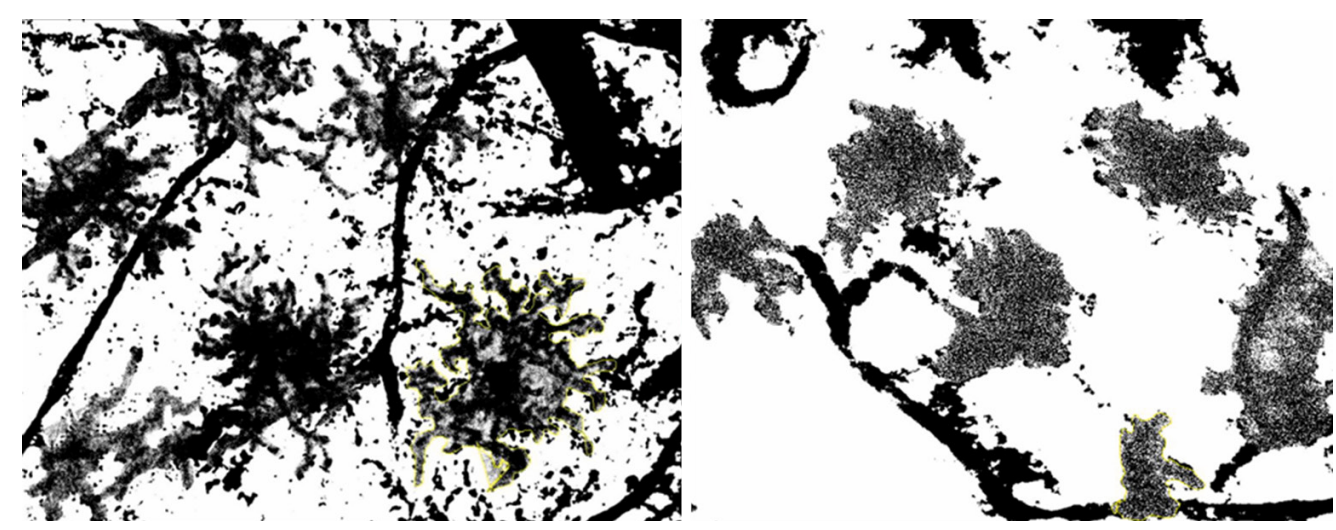

Figure 10. Hippocampal microglial cells (MGCs) transformation during venom exposure. Representative images of MGCs patterns for measurements of perimeter are shown

A

intact

$1 \mathrm{~h}$

$2 \mathrm{~h}$

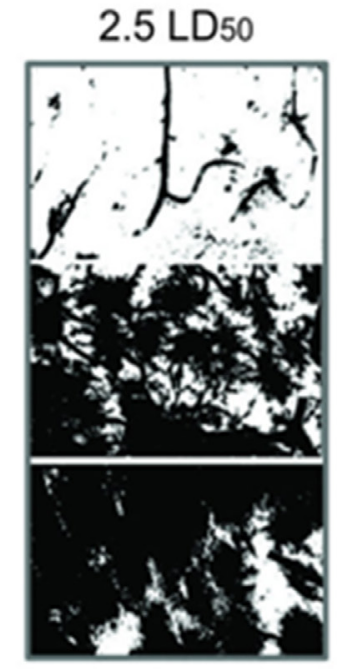

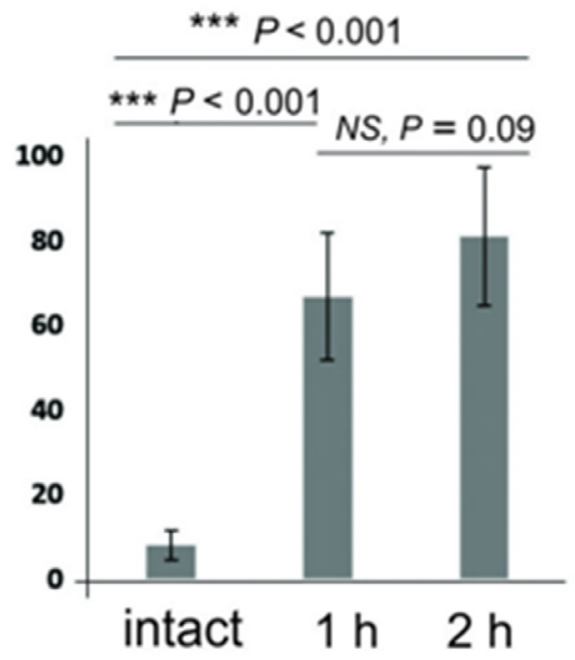

B

intact

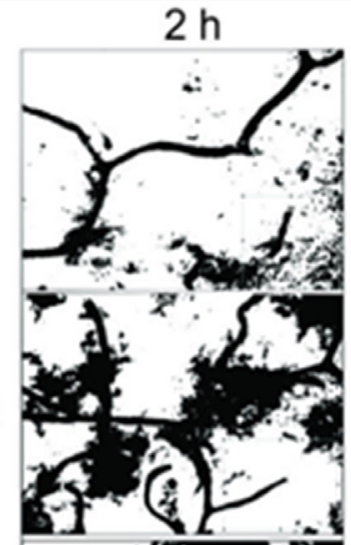

1.0 LD50
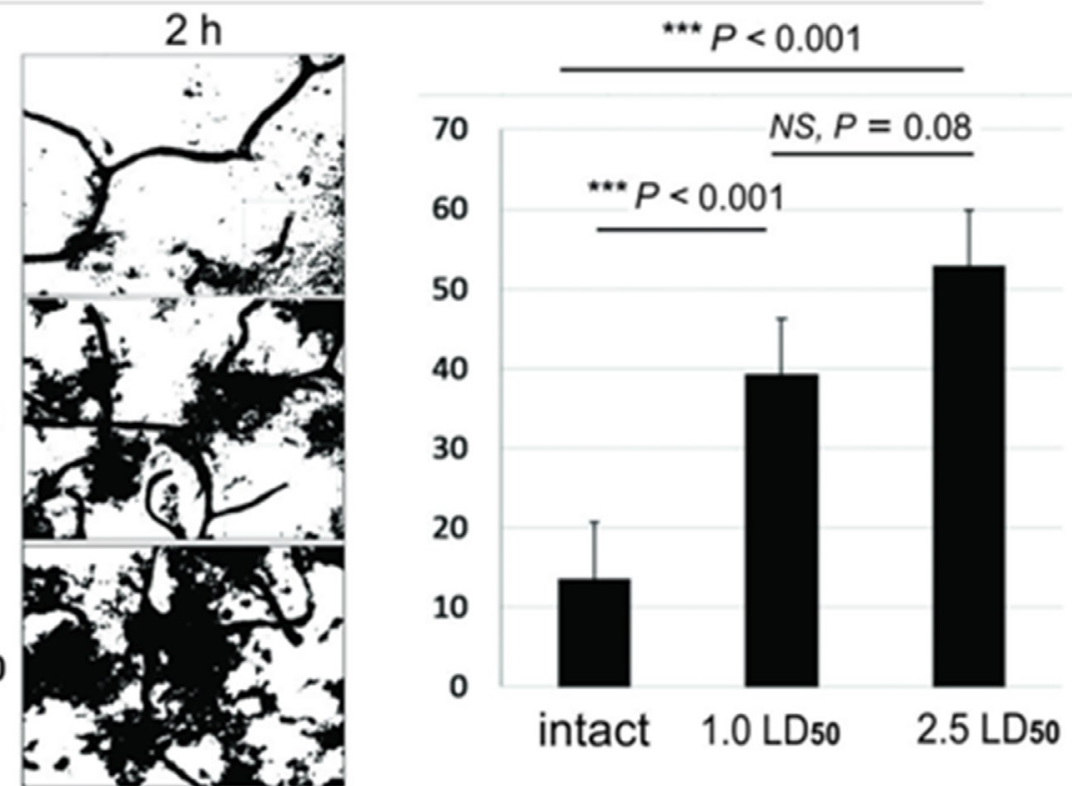

Figure 11. A: Quantification of ATPase activity in rat brain striatum after $2 \mathrm{~h}$ of $1.0 \mathrm{LD}_{50}$ and $2.5 \mathrm{LD}_{50}$ dose; B: quantification of ATPase activity in rat brain hippocampus after $1 \mathrm{~h}$ and $2 \mathrm{~h}$ of $2.5 \mathrm{LD}_{50}$ venom dose envenomation 
Table 2. Calculation of the quantitative parameters of the microglial cells in two groups in the hippocampus of rat brain

\begin{tabular}{|c|c|c|c|c|c|c|c|c|}
\hline \multirow{2}{*}{ Cell } & \multicolumn{4}{|c|}{ Six microglia cells, activated } & \multicolumn{4}{|c|}{ Six microglia cells, final stage } \\
\hline & Area & Mean & Min & Max & Area & Mean & Min & Max \\
\hline \multicolumn{9}{|c|}{ Rat brain, $1 \mathrm{~h}$ after Macrovipera lebetina obtusa injection, hippocampus } \\
\hline 1 & 28378 & 61.0 & 20 & 121 & & & & \\
\hline 2 & 24150 & 98.5 & 3 & 243 & & & & \\
\hline 3 & 27466 & 49.5 & 17 & 140 & & & & \\
\hline 4 & 17743 & 99.9 & 2 & 235 & & & & \\
\hline 5 & 20302 & 95.1 & 0 & 235 & & & & \\
\hline 6 & 16146 & 96.8 & 1 & 232 & & & & \\
\hline Average & 22364 & 83.5 & 7 & 201 & & & & \\
\hline \multicolumn{9}{|c|}{ Rat brain, $2 \mathrm{~h}$ after MLO injection, hippocampus } \\
\hline 1 & & & & & 7126 & 86.0 & 6 & 228 \\
\hline 2 & & & & & 6503 & 85.0 & 4 & 228 \\
\hline 3 & & & & & 6810 & 86.0 & 4 & 219 \\
\hline 4 & & & & & 6690 & 85.6 & 4 & 214 \\
\hline 5 & & & & & 6009 & 87.6 & 2 & 227 \\
\hline 6 & & & & & 6631 & 87.5 & 4 & 222 \\
\hline Average & & & & & 6628 & 86.3 & 4 & 223 \\
\hline
\end{tabular}

in response to acute or chronic stress and in experimental models of ischemia ${ }^{[33]}$. In addition, many studies explored the role of microglia in various models of neurodegenerative diseases such as Alzheimer's, Parkinson's, etc. ${ }^{[34]}$. MGCs are continuously scanning surroundings with their "tentacles" in every direction and in the case of detection of damage-associated molecules, stretch their processes in this direction. Based on our data, we presume that the routine scan does not consume much energy and does not lead to increased ATPase activity. However, in the case of envenomation, the MGC receives a signal about damage from astroglial cells ${ }^{[35]}$. It is known that special connexin hemichannels and $\mathrm{P} 2 \mathrm{Y}$ metabotropic purine receptors are activated and MGCs begin their movement toward damaged area ${ }^{[27]}$. Such partial or full activation of microglia naturally should lead to activation of enzymatic activity of ATPase and synthesis of new molecules of this enzyme to enable movement. In our investigation, the increased activity of ATPase in brain tissue of venom-exposed animals is detected. Simultaneous visualization of both the microcirculatory bed and activated microglia allows for detection of the distance and position between the capillaries and the MGC in hemorrhagic lesions upon MLO venom exposure. In the early stages of activation, the glial cells have a shape of a spider web and cell bodies are smaller compared with the area occupied by the whole cell ${ }^{[36]}$. These cells are approximately equidistant from nearby capillaries. At later stages of activation, MGCs become more rounded with a small number of "tentacles" and are located very close, or in direct contact with the nearest damaged vessel. The same phenomenon was described in the study of the early stage of multiple sclerosis: the authors observed the interaction of MGCs with capillaries when fibrinogen molecules diffuse from blood to brain tissue ${ }^{[37]}$. Animal studies also demonstrated that during venom exposure period microglia changes its shape and cells accumulate around blood vessels ${ }^{[32]}$.

Obtained data indicate varying degrees of involvement of microglia in the different regions of the brain during intoxication of prey's organism. This could be related to the anatomy of the blood supply paths, and with a specificity of ligands in different brain structures. Thus, the degree of activation of microglia and changes of its form, size, and position are good indicators of hemorrhage-induced cerebrovascular damage. Hemorrhagic effect of MLO venom on the brain tissue of rats is very similar to the hemorrhagic stroke developing in the human brain ${ }^{[38]}$. In some cases, systemic or local (intracerebral) injection of MLO venom may be used for hemorrhagic lesions modeling for experimental needs. Any alteration in brain tissue metabolism related to capillary damage activates microglial cells, which produce certain signaling molecules $^{[39,40]}$. The specific combination of such changes can serve as a diagnostic method to identify development of hemorrhage stroke, thus becoming an important clinical tool. 


\section{DECLARATIONS}

\section{Authors' contributions}

Conception, design, supervision, analysis and/or interpretation: Voskanyan A

Materials: Darbinyan A, Koshatashyan H, Gevorgyan S

Data collection and/or processing: Darbinyan A, Koshatashyan H, Antonyan M

Literature review: Voskanyan A, Antonyan M

Manuscript writing: Voskanyan A, Karabekyan Z, Arestakesyan H

Critical review: Ayvazyan N

\section{Availability of data and materials}

The datasets generated during and/or analysed during the current study are available from the corresponding author on reasonable request.

\section{Financial support and sponsorship}

None.

\section{Conflicts of interest}

Authors have no conflicts of interest related to this article. This research did not receive any specific grant from funding agencies in the public, commercial, or not-for-profit sectors.

\section{Ethical approval and consent to participate}

Not applicable.

\section{Consent for publication}

Not applicable.

\section{Copyright}

(c) The Author(s) 2018.

\section{REFERENCES}

1. Mackessy SP. Handbook of venoms and toxins of reptiles. Boca Raton: CRC Press/Taylor \& Francis; 2010. p. 95-207.

2. Sanz L, Ayvazyan N, Calvete JJ. Snake venomics of the Armenian mountain vipers Macrovipera lebetina obtusa and Vipera raddei. J Proteomics2008;71:198-209.

3. Hamza L, Gargioli C, Castelli S, Rufini S, Laraba-Djebari F. Purification and characterization of a fibrinogenolytic and hemorrhagic metalloproteinase isolated from Vipera lebetina venom. Biochimie 2010;92:797-805.

4. Tachoua W, Boukhalfa-Abib H, Laraba-Djebari F. Hemorrhagic metalloproteinase, Cc HSM-III, isolated from Cerastes cerastes venom: purification and biochemical characterization. J Biochem Mol Toxicol 2017; doi: 10.1002/jbt.21899.

5. Trummal K, Tõnismägi K, Siigur E, Aaspõllu A, Lopp A, Sillat T, Saat R, Kasak L, Tammiste I, Kogerman P, Kalkkinen N, Siigur J. A novel metalloprotease from Vipera lebetina venom induces human endothelial cell apoptosis. Toxicon 2005;46:46-61.

6. Fox JW, Gutiérrez JM. Understanding the snake venom metalloproteinases: an interview with Jay Fox and José María Gutiérrez. Toxins (Basel) 2017; doi: 10.3390/toxins9010033.

7. Gutiérrez JM, Rucavado A, Escalante T, Díaz C. Hemorrhage induced by snake venom metalloproteinases: biochemical and biophysical mechanisms involved in microvessel damage. Toxicon 2005;45:997-1011.

8. Wang WJ. Purification and functional characterization of AAV1, a novel P-III metalloproteinase, from Formosan Agkistrodon acutus venom. Biochimie 2007;89:105-15.

9. Song J, Xu X, Zhang Y, Guo M, Yan X, Wang S, Gao S. Purification and characterization of AHPM, a novel non-hemorrhagic P-IIIc metalloproteinase with $\alpha$-fibrinogenolytic and platelet aggregation-inhibition activities, from Agkistrodon halys pallas venom. Biochimie 2013;95:709-18.

10. Hsu CC, Huang TF. Biological activities of snake venom metalloproteinases on platelets, neutrophils, endothelial cells, and extracellular matrices. Dordrecht: Springer Science+Business Media B.V.; 2010. p. 723-32.

11. Wu WB, Huang TF. Activation of MMP-2, cleavage of matrix proteins, and adherens junctions during a snake venom metalloproteinase-induced endothelial cell apoptosis. Exp Cell Res 2003;288:143-57.

12. Page-McCaw A, Ewald AJ, Werb Z. Matrix metalloproteinases and the regulation of tissue remodelling. Nat Rev Mol Cell Biol 2007;8:221-33.

13. Deleon-Pennell KY, Altara R, Yabluchanskiy A, Modesti A, Lindsey ML. The circular relationship between matrix metalloproteinase-9 
and inflammation following myocardial infarction. IUBMB Life 2015;67:611-8.

14. Klebe D, McBride D, Flores JJ, Zhang JH, Tang J. Modulating the immune response towards a neuroregenerative peri-injury milieu after gerebral hemorrhage. J Neuroimmune Pharmacol 2015;10:576-86.

15. Kreutzberg GW. Microglia, the first line of defence in brain pathologies. Arzneimittelforschung 1995;45:357-60.

16. Streit WJ, Walter SA, Pennell NA. Reactive microgliosis. Prog Neurobiol 1999;57:563-81.

17. Kondo H, Kondo S, Irezawa H, Murata R. Studies on the quantitative method for determination of hemorrhagic activity of Habu snake venom. Jpn J Med Sci Biol 1960;13:43-52.

18. Randhawa MA. Calculation of LD50 values from the method of Miller and Tainter, 1944. J Ayub Med Coll Abbottabad 2009;21:184-5.

19. Chilingaryan A, Chilingaryan AM, Martin GG. The three-dimensional detection of microvasculatory bed in the brain of white rat Rattus norvegicus by a Ca2+-ATPase method. Brain Res 2006;1070:131-8.

20. Paxinos G, Watson C. The rat brain in stereotaxic coordinates. 6th ed. Amsterdam: Elsevier; 2007.

21. Abràmoff MD, Magalhães PJ, Ram SJ. Image Processing with ImageJ. Biophotonics Int 2004;11:36-42.

22. Archundia IG, de Roodt AR, Ramos-Cerrillo B, Chippaux JP, Olguín-Pérez L, Alagón A, Stock RP. Neutralization of Vipera and Macrovipera venoms by two experimental polyvalent antisera: a study of paraspecificity. Toxicon 2011;57:1049-56.

23. Kurtović T, Lang Balija M, Ayvazyan N, Halassy B. Paraspecificity of Vipera a. ammodytes-specific antivenom towards Montivipera raddei and Macrovipera lebetina obtusa venoms. Toxicon 2014;78:103-12.

24. Bell KL, Sutherland SK, Hodgson WC. Some pharmacological studies of venom from the inland taipan (Oxyuranus microlepidotus). Toxicon 1998;36:63-74.

25. Perry VH, Teeling J. Microglia and macrophages of the central nervous system: the contribution of microglia priming and systemic inflammation to chronic neurodegeneration. Semin Immunopathol 2013;35:601-12.

26. Graeber MB, Li W, Rodriguez ML. Role of microglia in CNS inflammation. FEBS Lett 2011;585:3798-805.

27. Kettenmann H, Verkhratsky A. Neuroglia--living nerve glue. Fortschr Neurol Psychiatr 2011;79:588-97.

28. Calvete JJ, Sanz L, Angulo Y, Lomonte B, Gutiérrez JM. Venoms, venomics, antivenomics. FEBS Lett 2009;583:1736-43.

29. Tremblay MÈ, Stevens B, Sierra A, Wake H, Bessis A, Nimmerjahn A. The role of microglia in the healthy brain. J Neurosci 2011;31:16064-9.

30. Wake H, Moorhouse AJ, Jinno S, Kohsaka S, Nabekura J. Resting microglia directly monitor the functional state of synapses in vivo and determine the fate of ischemic terminals. J Neurosci 2009;29:3974-80.

31. Wan S, Cheng Y, Jin H, Guo D, Hua Y, Keep RF, Xi G. Microglia activation and polarization after intracerebral hemorrhage in mice: the role of protease-activated receptor-1. Transl Stroke Res 2016;7:478-87.

32. Gyoneva S, Davalos D, Biswas D, Swanger SA, Garnier-Amblard E, Loth F, Akassoglou K, Traynelis SF. Systemic inflammation regulates microglial responses to tissue damage in vivo. Glia 2014;62:1345-60.

33. Walker FR, Nilsson M, Jones K. Acute and chronic stress-induced disturbances of microglial plasticity, phenotype and function. Curr Drug Targets 2013;14:1262-76.

34. Block ML, Hong JS. Microglia and inflammation-mediated neurodegeneration: multiple triggers with a common mechanism. Prog Neurobiol 2005;76:77-98.

35. Tremblay MÈ, Lecours C, Samson L, Sánchez-Zafra V, Sierra A. From the Cajal alumni Achúcarro and Río-Hortega to the rediscovery of never-resting microglia. Front Neuroanat 2015;9:45.

36. Hovens IB, Nyakas C, Schoemaker RG. A novel method for evaluating microglial activation using ionized calcium-binding adaptor protein-1 staining: cell body to cell size ratio. Neuroimmunol Neuroinflammation 2014;1:82-8.

37. Chodobski A, Zink BJ, Szmydynger-Chodobska J. Blood-brain barrier pathophysiology in traumatic brain injury. Transl Stroke Res 2011;2:492-516.

38. Florczak-Rzepka M, Grond-Ginsbach C, Montaner J, Steiner T. Matrix metalloproteinases in human spontaneous intracerebral hemorrhage: an update. Cerebrovasc Dis 2012;34;249-62.

39. Bilbo SD, Schwarz JM. Early-life programming of later-life brain and behavior: a critical role for the immune system. Front Behav Neurosci 2009;3:14

40. Bell-Temin H, Culver-Cochran AE, Chaput D, Carlson CM, Kuehl M, Burkhardt BR, Bickford PC, Liu B, Stevens SM Jr. Novel molecular insights into classical and alternative activation states of microglia as revealed by stable isotope labeling by amino acids in cell culture (silac)-based proteomics. Mol Cell Proteomics 2015;14:3173-84. 